\title{
Retrospective comparative clinical study for silk mat application into extraction socket
}

\author{
Ju-Won Kim ${ }^{1 \dagger}$, You-Young Jo ${ }^{2 \dagger}$, Jwa-Young Kim³ ${ }^{3}$, Ji-hyeon $\mathrm{Oh}^{4}$, Byoung-Eun Yang ${ }^{1}$ and Seong-Gon Kim ${ }^{4}$ (D)
}

\begin{abstract}
Background: Silk mats have been approved for clinical trials by the Korean Food and Drug Administration as membranes for guided tissue regeneration (GTR). In this study, silk mat application was compared to high-density polytetrafluoroethylene (dPTFE) membrane application or no membrane group.

Methods: To compare the silk mat group to the dPTFE group or the no membrane group, a retrospective sample collection was conducted. Bony defects were measured at the time of extraction (T0) and then at 3 months (T1) and 6 months after extraction (T2) on a digital panoramic view. Bone gain (BG) was calculated by subtracting from the bony defect at T0 to the bony defect at each follow-up.
\end{abstract}

Results: The BG at T2 was $2.44 \pm 2.49 \mathrm{~mm}, 4.18 \pm 1.80 \mathrm{~mm}$, and $4.24 \pm 2.05 \mathrm{~mm}$ in the no membrane group, silk mat group, and dPTFE group, respectively. Both membrane groups had significantly higher BG than BG in the no membrane group at T2 $(P<0.05)$.

Conclusions: Both membrane groups showed higher BG than the no membrane group.

Keywords: Guided tissue regeneration, Silk mat, Polytetrafluoroethylene, Probing depth, Bone gain

\section{Background}

Third molar surgery is the most frequent procedure in the department of oral and maxillofacial surgery $[1,2]$. The complications associated with third molar surgery are classified as early-onset and late-onset [3]. Deep pocket formation adjacent to the second molar is a late-onset complication. This periodontal defect is frequent in cases of deeply impacted lower third molar surgery $[4,5]$. Although the systemic condition of the patient may influence this complication [6, 7], the local environment in the impacted teeth is the main etiologic factor [5]. This impaired bone defect is associated with a critical-sized bone defect and may require treatment via graft $[8,9]$.

Collagen-based plugs have been used for ridge preservation and may be used for third molar surgery. Graft with bone substitute is also considered a preventive measure. However, these materials may be a source for postoperative infection and not be helpful. Different types of membranes have been shown to be reliable. Biodegradable or

\footnotetext{
* Correspondence: kimsg@gwnu.ac.kr

Ju-Won Kim and You-Young Jo contributed equally.

${ }^{4}$ Department of Oral and Maxillofacial Surgery, College of Dentistry,

Gangneung-Wonju National University, Gangneung 28644, Republic of Korea Full list of author information is available at the end of the article
}

non-degradable membranes have been introduced. Both types of membranes have been shown a similar outcome [10]. The success rate is associated with the presence of membrane exposure [11]. High-density polytetrafluoroethylene (dPTFE) is introduced for cases with a potential risk of membrane exposure [12].

Silk mat is produced from silkworm cocoon by a simple peeling-off method [13, 14]. Silk mat is mainly composed of fibroin and sericin. Because sericin is a hydrophilic bonding protein that is slowly degraded in water, fragmented sericin is released from silk mats continuously [14]. These sericin fragments are helpful for bone regeneration via a cellular-mediated response [14]. Because silk-based materials have been considered bio-inert and cyto-compatible, silk materials are the main source of scaffolds for bone tissue engineering [15]. As fibroin is resistant to biodegradation, silk mat is classified as non-biodegradable and approved for clinical trials by the Korean Food and Drug Administration (KFDA; Approval number: SPENSER-TS101, approved on November 27, 2015).

The aim of this study was to compare the bone regeneration of the silk mat group to the positive control and 
negative control in the mandibular third molar defect. As a positive control, the dPTFE membrane group was used. Patients who did not receive the membrane were also recruited as negative controls. Accordingly, a comparison between the membrane-applied groups and the no membrane group was performed.

\section{Patients and methods}

\section{Collection of data}

Retrospective data collection was performed for comparison with membrane-applied groups. The data for the membrane groups had been collected during previous clinical trials. In previous clinical trials, silk mat was provided by Spencer biomedical technology (Seoul, Korea) (Fig. 1). Cytoplast TXT-200 (Biohorizons, Birmingham, AL, USA) was used for dPTFE membrane. Retrospective unnamed data collection for the no membrane group was approved by the institutional review board of Gangneung-Wonju National University Dental Hospital (IRB No. 2018-003). Clinical trials' data from the membrane-applied group were provided by Sacred Heart Hospital, Hallym University. This study was performed by chart review. No direct identifiers were recorded on the data sheet. Patients' chart data were used only for determining inclusion in the analysis. The data in picture archiving and communication systems were also used for evaluating the mandibular third molar and measuring bone defects before and after extraction.

The inclusion criteria were (1) patients with impacted mandibular third molars, (2) American Society of Anesthesiologists (ASA) physical status I or II, (3) 20 to $<40$ years old, (4) present minimum 3-mm bony defect in the distal surface of the mandibular second molar and minimum 5-mm pocket depth in the distal surface of the mandibular second molar at the time of extraction, and (5) patients with a preoperative panoramic view and postoperative panoramic view at either T1 or T2. The exclusion criteria were (1) age $<20$ or $>40$ years, (2) smokers, (3) patients having any systemic disease, (4) patients receiving irradiation in the head and neck area, (5) patients having malignant cancer history, (6) patients having any oral mucosal disease, and (7) patients having poor oral hygiene. The amount of bony defect was measured on the panoramic view. The distance between the cement-enamel junction and the bottom of the bony defect on the distal surface of the second molar was measured using SigmaScan Pro (SPSS Inc., Chicago, IL, USA) and defined as a bony defect (Fig. 2). Bone gain (BG) was defined as a preoperative bony defect minus a bony defect at follow-up. In cases of T2 samples, any radiogram taken over 12 months after extraction was also excluded.

\section{Statistical analysis}

The comparison of bone level in the same patient at the different observation points of the no membrane group was performed by a paired sample $t$ test. An analysis of variance was used in the comparison of BG between the membrane groups and the no membrane group. Bonferroni's test was used for post hoc analysis. The level of significance was set at $P<0.05$.

\section{Results}

The numbers of patients in the membrane groups were 25 (average age 24.0 \pm 3.6 years, female 18, male 7). All patients from the membrane groups had panoramic views at T0, T1, and $\mathrm{T} 2$. For the no membrane group, panoramic views were collected retrospectively. All patients had a panoramic view
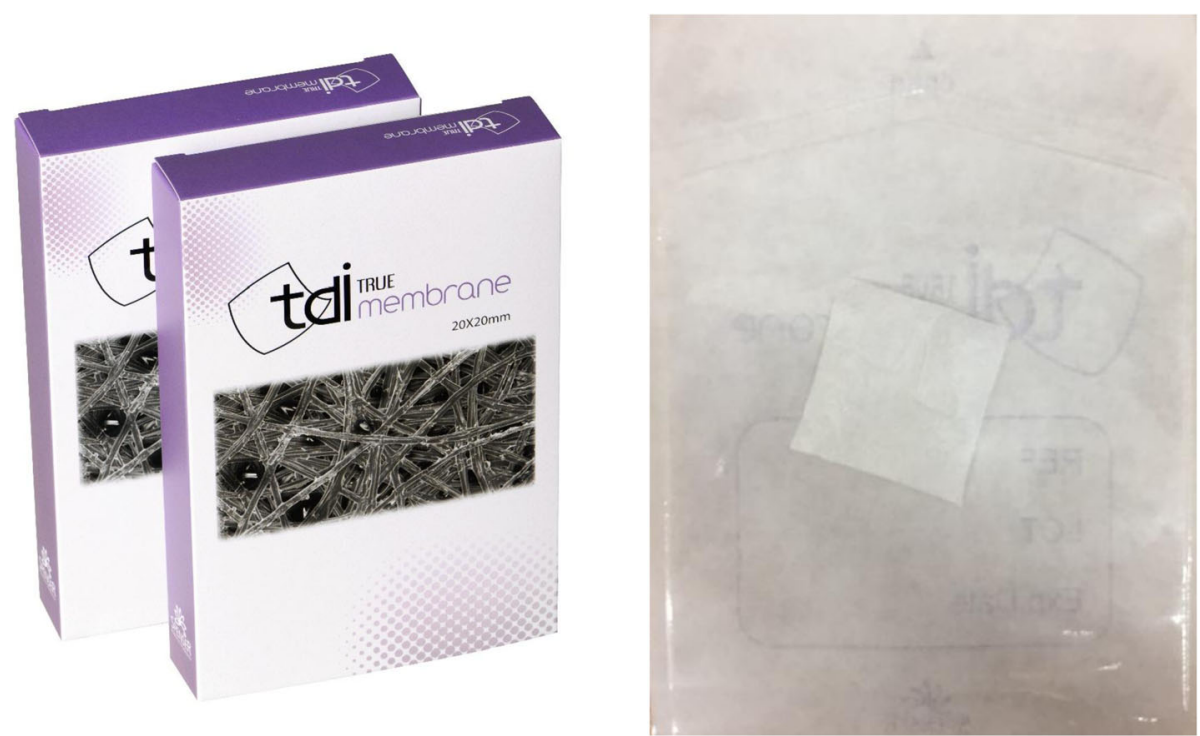

Fig. 1 Commercialized silk mat used for this study 

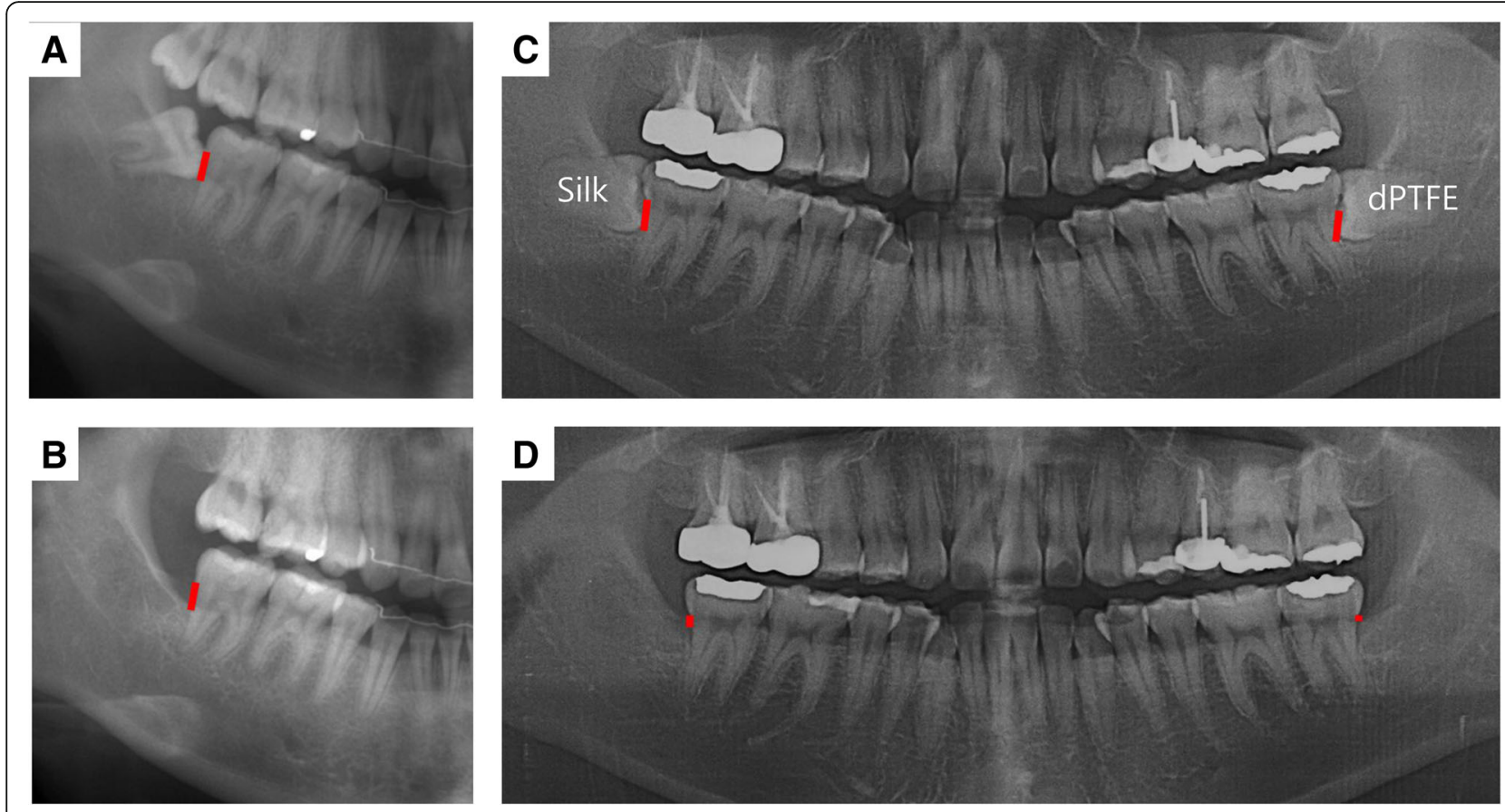

Fig. 2 Measurement of the bony defect. Bony defect is the distance between the cement-enamel junction and the bottom of the bony defect on the distal surface of the second molar. The amount of a bony defect is indicated as a red bar on the panoramic view. a No membrane group before extraction. b No membrane group at 6 months after extraction. c Membrane group before extraction. The patient had bilaterally impacted third molar. In this patient, silk mat was applied to the right side and dPTFE to the left side. $\mathbf{d}$ Membrane group at 6 months after extraction

at T0. The number of patients with panoramic view at T1 was 35 (average age $25.8 \pm 4.4$ years, female 25 , male 10 ). The size of the bony defect at T0 for this group was $7.35 \pm$ $1.23 \mathrm{~mm}$ (Table 1). The number of patients with panoramic view at T2 was 35 (average age $25.1 \pm 5.3$ years, female 19 , male 16). The size of the bony defect at T0 for this group was $7.36 \pm 2.12 \mathrm{~mm}$ (Table 1). There was no significant difference in patients' age and sex among the groups $(P>0.05)$. The mean follow-up for the no membrane group at $\mathrm{T} 1$ was $3.08 \pm 0.37$ months, and at $\mathrm{T} 2$, it was $7.03 \pm 1.44$ months. When compared bony defect size in T0 to $\mathrm{T} 1$ or T0 to T2 for the no membrane group, the difference between groups was statistically significant $(P<0.001)$.

The size of the bony defect at T0 was $6.47 \pm 2.11$ and $6.46 \pm 2.05 \mathrm{~mm}$ in the dPTFE group and the silk mat group, respectively (Table 2). There was no significant difference in the size of the bony defect between groups at T0 $(P>0.05)$. When compared bony defect size in T0 to $\mathrm{T} 1$ or $\mathrm{T} 0$ to $\mathrm{T} 2$ for the membrane groups, the difference between groups was statistically significant $(P<0.001)$.

Table 1 Summary of bone defect in patients without graft

\begin{tabular}{lllll}
\hline Number & T0 $(\mathrm{mm})$ & T1 $(\mathrm{mm})$ & T2 $(\mathrm{mm})$ & $P$ value \\
\hline 35 & $7.35 \pm 1.23$ & $5.89 \pm 1.26$ & - & $<0.001$ \\
35 & $7.36 \pm 2.12$ & - & $4.92 \pm 2.79$ & $<0.001$
\end{tabular}

TO immediate after extraction, $T 13$ months after extraction, $T 26$ months after extraction
The BG in the no membrane group was $1.47 \pm 0.50$ and $2.44 \pm 2.49 \mathrm{~mm}$ at $\mathrm{T} 1$ and $\mathrm{T} 2$, respectively (Fig. 3). The BG in the APTFE membrane group was $2.06 \pm 1.39$ and 4.24 $\pm 2.05 \mathrm{~mm}$ at $\mathrm{T} 1$ and T2, respectively (Fig. 3). The BG in the silk mat group was $2.57 \pm 1.68$ and $4.18 \pm 1.80 \mathrm{~mm}$ at $\mathrm{T} 1$ and T2, respectively (Fig. 3 ). When bone gain was compared among the groups, there was a significant difference at both 3 and 6 months $(P=0.008$ and 0.002 , respectively). In the post hoc test, the silk mat group showed significantly higher BG than the no membrane group at T1 $(P=0.006)$. Both the silk mat group and the dPTFE group showed significantly higher $B G$ than the no membrane group at T2 $(P=0.011$ and 0.008 , respectively). There was no significant difference in BG between the silk mat and dPTFE groups at T1 and T2 $(P>0.05)$.

\section{Discussion}

Silk mat has been widely studied as a membrane for guided tissue regeneration (GTR) [13, 15]. Silk mat shows a similar level of bone regeneration compared to collagen membrane in the animal model [16]. In this clinical study, silk mats showed similar levels of bone regeneration compared to dPTFE membranes (Fig. 3). Both silk mat and dPTFE membrane showed better bone regeneration compared to the non-graft/membrane group (Fig. 3). To the best of our knowledge, this is the first clinical comparative study of silk mats. 
Table 2 Summary of bone defect in patients with membrane

\begin{tabular}{|c|c|c|c|c|c|c|}
\hline \multirow[t]{2}{*}{ Group } & \multirow[t]{2}{*}{ Number } & \multirow[t]{2}{*}{ T0 (mm) } & \multirow[t]{2}{*}{$\mathrm{T1}(\mathrm{mm})$} & \multirow[t]{2}{*}{$\mathrm{T} 2(\mathrm{~mm})$} & \multicolumn{2}{|l|}{$P$ value } \\
\hline & & & & & T0 to T1 & T0 to T2 \\
\hline dPTFE & 25 & $6.47 \pm 2.11$ & $4.41 \pm 1.69$ & $2.23 \pm 0.85$ & $<0.001$ & $<0.001$ \\
\hline Silk mat & 25 & $6.46 \pm 2.05$ & $3.89 \pm 1.25$ & $2.28 \pm 1.13$ & $<0.001$ & $<0.001$ \\
\hline
\end{tabular}

TO immediate after extraction, T1 3 months after extraction, T2 6 months after extraction

The bony defect in the distal surface of the mandibular second molar can be induced by impacted third molar [2]. The size of the defect is dependent on the local environment adjacent to the impacted teeth, such as the degree of impaction, oral hygiene, and systemic disease [2, 4]. If the bony defect after the third molar removal is not reached at the critical-sized defect (CSD), it will be healed without applying graft. To the best of our knowledge, there has been no volumetric analysis for CSD in human third molar surgery. Pocket depth in the distal surface of the second molar has been used as an indicator for CSD determination. In this study, patients with a minimum 3-mm bony defect were included [17]. In our study, the BG for the nonregenerative/nongraft procedure group was $1.4 \mathrm{~mm}$ and $2.5 \mathrm{~mm}$ at 3 and 6 months, respectively (Fig. 3). The application of PTFE has been shown to improve tissue regeneration compared to the nonregenerative/nongraft procedure group $[18,19]$. Additional bone grafts with GTR do not show a synergistic effect after extraction [19].

Silk mat has many benefits compared to other types of membrane. The tensile strength in wet conditions is higher in silk mats than in collagen membranes and dPTFE membranes [16]. Considering the presence of saliva in the oral cavity, the high tensile strength of silk mat in wet conditions is beneficial for clinicians to manage. The production procedure for silk mats is simple
[15]. Accordingly, the price for silk mat is also expected to be cheap compared to other types of membrane. The price of material has been an obstacle for the application of membrane in third molar surgery. In addition, silk sericin has bone regeneration ability [20]. Silk mat contains abundant silk sericin as its natural form [14].

In this study, panoramic radiogram was used to measure bone height at the distal surface of the mandibular second molar. Panoramic radiograms have different magnification ratios according to the anatomic site [21]. The shape of jaw bones may also influence image sharpness. Compared to cone-beam computerized tomograms $(\mathrm{CBCT})$, error due to image distortion is higher in panoramic radiograms [21]. However, measurement in panoramic radiographs is highly correlated with that in $\mathrm{CBCT}$ and can be used in the posterior alveolus of the mandible [22]. However, CT has three-dimensional and multiple slices of images. Averaging bony defects along the distal surface of the second molar will be time-consuming. As panoramic radiogram is a two-dimensional image, it may have a benefit for measuring the average distance of the overlapped structure. The linear measurements show similar accuracy between CBCT and digital panoramic view [23].

The limitation of this study was that the samples in the control group (nonregenerative/nongraft procedure) were collected separately from 3 months and 6 months because most patients did not have postoperative follow-up

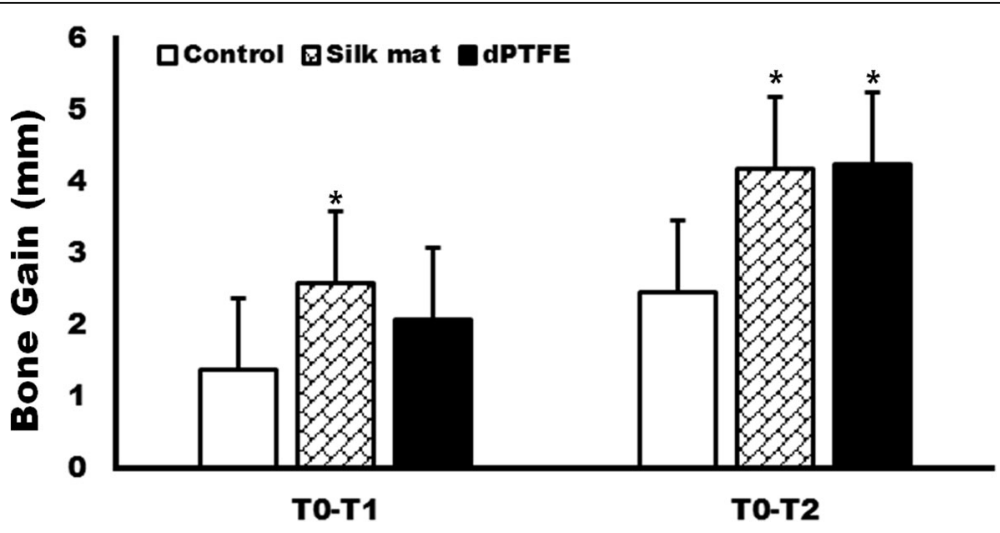

Fig. 3 The amount of bone gain (BG) at 3 months (T1) and 6 months after tooth extraction (T2). In a post hoc test, BG in the silk mat group showed a significantly higher gain compared with the control group (nonregenerative/nongraft procedure) at T1. Both membrane groups showed significantly higher BG than the control group (nonregenerative/nongraft procedure) at T2 $\left({ }^{*} P<0.05\right)$ 
radiograms. Accordingly, the controls at 3 months and at 6 months were different. In future studies, the samples for control should also be collected prospectively and in a controlled manner.

\section{Conclusion}

Silk mat showed similar clinical performance to dPTFE when it was used for GTR in the extraction socket. Both membrane groups showed higher BG than the no membrane group experienced.

\section{Abbreviations}

BG: Bone gain; CBCT: Cone-beam computerized tomogram; dPTFE: Highdensity polytetrafluoroethylene; GTR: Guided tissue regeneration; KFDA: Korean Food and Drug Administration

\section{Acknowledgements}

Authors thanks to Dr. Seung-Ho Shin and Dr. Ye-Jin Kang for their help in collecting samples in the control group. This work was carried out with the support of "Cooperative Research Program for Agriculture Science and Technology Development (Project no. PJ01313902)" Rural Development Administration, Republic of Korea.

\section{Funding}

This work was carried out with the support of "Cooperative Research Program for Agriculture Science and Technology Development (Project no. PJ01313902)" Rural Development Administration, Republic of Korea.

\section{Availability of data and materials}

All data were shown in this manuscript.

\section{Authors' contributions}

This study was designed by JYY, YBE, and KSG. YBE, KJW, and KJY did clinical trials and data analysis. OJ collected untreated control samples and did the radiogram analysis. KJW, JYY, and KSG wrote a manuscript and performed the critical review. All authors read and approved the final manuscript.

\section{Ethics approval and consent to participate}

Retrospective data collection was done for the comparison with membraneapplied groups. Retrospective unnamed data collection was approved by the institutional review board of Gangneung-Wonju National University Dental Hospital (IRB No. 2018-003).

\section{Consent for publication}

This manuscript does not contain any individual person's identifier (including individual details, images or videos).

\section{Competing interests}

Spencer biomedical technology, which manufactures TDI, provided the membrane for free and provided personnel support via an investigatorsponsored research agreement to YBE. The authors declare that the authors have no competing interests as defined by Nature Research, or other interests that might be perceived to influence the results and/or discussion reported in this paper.

\section{Publisher's Note}

Springer Nature remains neutral with regard to jurisdictional claims in published maps and institutional affiliations.

\section{Author details}

'Department of Oral and Maxillofacial Surgery, Sacred Heart Hospital, Hallym University, Anyang 14068, Republic of Korea. ${ }^{2}$ Sericultural and Apicultural Division, National Institute of Agricultural Science, RDA, Wanju 55365, Republic of Korea. ${ }^{3}$ Department of Oral and Maxillofacial Surgery, Hallym University Kangnam Sacred Heart Hospital, Seoul 07441, Republic of Korea. ${ }^{4}$ Department of Oral and Maxillofacial Surgery, College of Dentistry, Gangneung-Wonju National University, Gangneung 28644, Republic of Korea.
Received: 11 February 2019 Accepted: 18 March 2019

Published online: 12 April 2019

\section{References}

1. Kim SY et al (2017) Extraction socket sealing using palatal gingival grafts and resorbable collagen membranes. Maxillofac Plast Reconstr Surg 39:39

2. Nunn ME et al (2013) Retained asymptomatic third molars and risk for second molar pathology. J Dent Res 92:1095-1099

3. Kim JC, Choi SS, Wang SJ, Kim SG (2006) Minor complications after mandibular third molar surgery: type, incidence, and possible prevention. Oral Surg Oral Med Oral Pathol Oral Radiol Endod 102:e4-e11

4. Kugelberg CF, Ahlstrom U, Ericson S, Hugoson A, Kvint S (1991) Periodontal healing after impacted lower third molar surgery in adolescents and adults. A prospective study. Int J Oral Maxillofac Surg 20:18-24

5. Karapataki S, Hugoson A, Kugelberg CF (2000) Healing following GTR treatment of bone defects distal to mandibular 2nd molars after surgical removal of impacted 3rd molars. J Clin Periodontol 27:325-332

6. Dodson TB (2005) Is there a role for reconstructive techniques to prevent periodontal defects after third molar surgery? J Oral Maxillofac Surg 63:891-896

7. Kumar $\mathrm{N}$ et al (2015) Evaluation of treatment outcome after impacted mandibular third molar surgery with the use of autologous platelet-rich fibrin: a randomized controlled clinical study. J Oral Maxillofac Surg 73:1042-1049

8. Chen YW, Lee CT, Hum L, Chuang SK (2017) Effect of flap design on periodontal healing after impacted third molar extraction: a systematic review and meta-analysis. Int J Oral Maxillofac Surg 46:363-372

9. Lee CT, Hum L, Chen YW (2016) The effect of regenerative periodontal therapy in preventing periodontal defects after the extraction of third molars: a systematic review and meta-analysis. J Am Dent Assoc 147:709-719

10. Karapataki S, Hugoson A, Falk H, Laurell L, Kugelberg CF (2000) Healing following GTR treatment of intrabony defects distal to mandibular 2nd molars using resorbable and non-resorbable barriers. J Clin Periodontol 27: 333-340

11. Barboza EP, Stutz B, Ferreira VF, Carvalho W (2010) Guided bone regeneration using nonexpanded polytetrafluoroethylene membranes in preparation for dental implant placements-a report of 420 cases. Implant Dent 19:2-7

12. Barber HD, Lignelli J, Smith BM, Bartee BK (2007) Using a dense PTFE membrane without primary closure to achieve bone and tissue regeneration. J Oral Maxillofac Surg 65:748-752

13. Kim SG et al (2016) Comparison of unprocessed silk cocoon and silk cocoon middle layer membranes for guided bone regeneration. Maxillofac Plast Reconstr Surg 38:11

14. Jo YY et al (2017) Bone regeneration is associated with the concentration of tumour necrosis factor-alpha induced by sericin released from a silk mat. Sci Rep 7:15589

15. Kweon $\mathrm{H}$ et al (2017) In vivo bone regeneration ability of different layers of natural silk cocoon processed using an eco-friendly method. Macromol Res 25:806-816

16. Ha YY, Park YW, Kweon H, Jo YY, Kim SG (2014) Comparison of the physical properties and in vivo bioactivities of silkworm-cocoon-derived silk membrane, collagen membrane, and polytetrafluoroethylene membrane for guided bone regeneration. Macromol Res 22:1018-1023

17. Corinaldesi G, Lizio G, Badiali G, Morselli-Labate AM, Marchetti C (2011) Treatment of intrabony defects after impacted mandibular third molar removal with bioabsorbable and non-resorbable membranes. J Periodontol 82:1404-1413

18. Pecora G, Celletti R, Davarpanoh M, Covani U, Etienne D (1993) The effects of guided tissue regeneration on healing after impacted mandibular thirdmolar surgery: 1-year results. Int J Periodont Restor Dent 13:396-407

19. Barbato $L$ et al (2016) Effect of surgical intervention for removal of mandibular third molar on periodontal healing of adjacent mandibular second molar: a systematic review and Bayesian network meta-analysis. J Periodontol 87:291-302

20. Nayak S, Dey T, Naskar D, Kundu SC (2013) The promotion of osseointegration of titanium surfaces by coating with silk protein sericin Biomaterials 34:2855-2864

21. Sahota J, Bhatia A, Gupta M, Singh V, Soni J, Soni R (2017) Reliability of orthopantomography and cone-beam computed tomography in presurgical implant planning: a clinical study. J Contemp Dent Pract 18:665-669 
22. Shahidi S, Zamiri B, Abolvardi M, Akhlaghian M, Paknahad M (2018) Comparison of dental panoramic radiography and $\mathrm{CBCT}$ for measuring vertical bone height in different horizontal locations of posterior mandibular alveolar process. J Dent (Shiraz) 19:83-91

23. Luangchana P, Pornprasertsuk-Damrongsri S, Kiattavorncharoen S, Jirajariyavej B (2015) Accuracy of linear measurements using cone beam computed tomography and panoramic radiography in dental implant treatment planning. Int J Oral Maxillofac Implants 30:1287-1294

Submit your manuscript to a SpringerOpen ${ }^{\circ}$ journal and benefit from:

- Convenient online submission

- Rigorous peer review

- Open access: articles freely available online

- High visibility within the field

- Retaining the copyright to your article

Submit your next manuscript at $\boldsymbol{\sim}$ springeropen.com 